\title{
Erratum to: Watt-level red-emitting diode lasers and modules for display applications
}

\author{
Katrin Paschke $^{1} \cdot$ Gunnar Blume $^{1} \cdot$ David Feise $^{1} \cdot$ Johannes Pohl $^{1}$. \\ Bernd Sumpf ${ }^{1}$
}

Published online: 21 January 2016

(C) The Optical Society of Japan 2016

\section{Erratum to: Opt Rev \\ DOI 10.1007/s10043-015-0157-7}

Unfortunately, there was an error in the original publication of the article. The data points in Fig. 6a were not recorded at $15{ }^{\circ} \mathrm{C}$, but at $5{ }^{\circ} \mathrm{C}$.

The corrected caption of Fig. 6 as follows:

Fig. 6 Power-current characteristics of master oscillator power amplifier at $635 \mathrm{~nm}$ (a) and at $647 \mathrm{~nm}$ (b). The characteristics were measured at $5{ }^{\circ} \mathrm{C}$ (a) and at $15{ }^{\circ} \mathrm{C}$ (b) (inset schematics of a MOPA)

The online version of the original article can be found under doi:10.1007/s10043-015-0157-7.

\section{Gunnar Blume}

gunnar.blume@fbh-berlin.de

1 Ferdinand-Braun-Institut, Leibniz-Institut für Höchstfrequenztechnik, Gustav-Kirchhoff-Str. 4, 12489 Berlin, Germany 